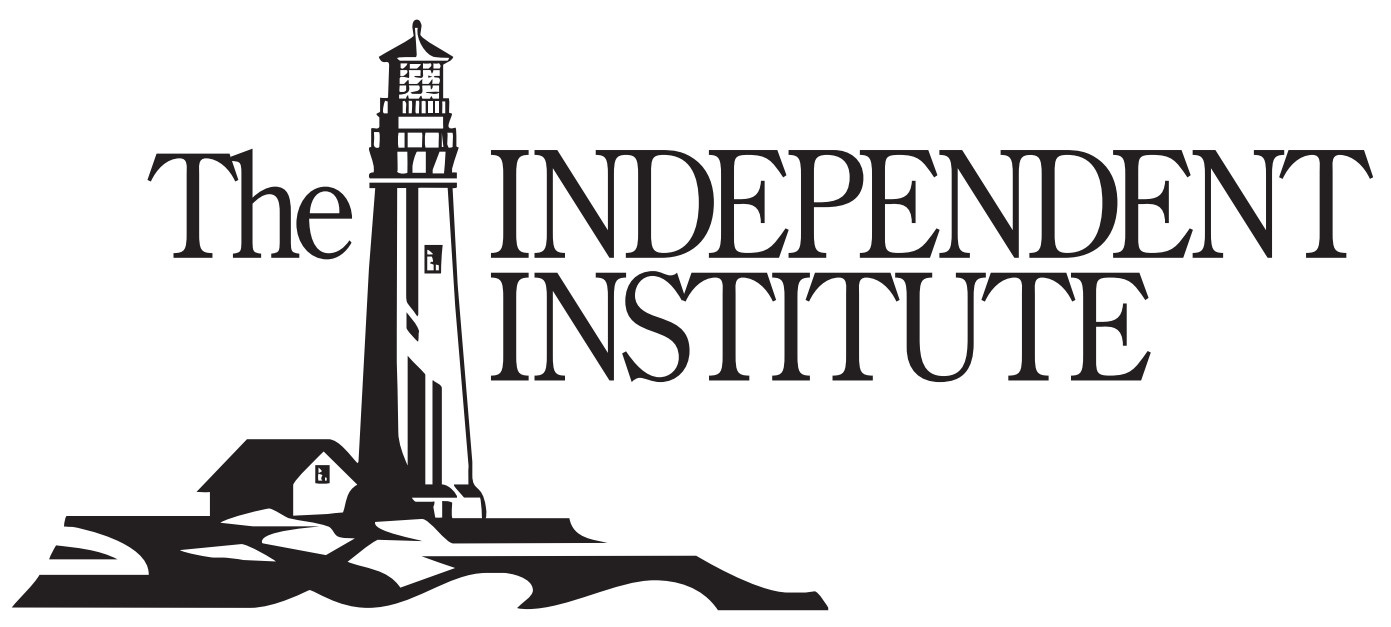

$\frac{\text { Wow } \frac{\text { When Is Two Better than One? }}{\text { Federalism Mitigates and Intensifies }}}{\underline{\text { Imperfect Political Competition }}}$

Independent Institute Working Paper \#5

Bryan Caplan

October 1999 


\title{
When Is Two Better than One? \\ How Federalism Mitigates and Intensifies Imperfect Political Competition
}

\author{
Bryan Caplan \\ Department of Economics \\ and Center for Study of Public Choice \\ George Mason University \\ Fairfax, VA 22030 \\ bcaplan@gmu.edu \\ 703-993-2324
}

JEL Classifications: D72, H11, D60

Keywords: optimal federalism, imperfect political competition, intergovernmental competition

The current paper models power-maximizing politicians' behavior subject to imperfect political competition and perfect citizen mobility. It then analyzes the welfare implications of federal and non-federal structures. The model abstracts from both heterogeneous preferences (the most common argument in favor of federalism) and externalities (the most common argument against), showing that even in this simplified setting federalism has important welfare implications. There is one class of equilibria in which more federalism has the purely beneficial effect of offsetting imperfections in the political process. However, there is also a second class of equilibria in which citizen mobility makes political imperfections more severe by creating "safe districts" for both political parties.

I would like to thank my advisor, Anne Case, as well as Igal Hendel, David Bradford, Robert Willig, Harvey Rosen, Alessandro Lizzeri, Gordon Dahl, Sam Peltzman, Tom Nechyba, Tyler Cowen, Bill Dickens, Yesim Yilmaz, Roger Gordon, David Levy, Robin Hanson, two anonymous referees, and seminar participants at Princeton and George Mason for numerous helpful comments and suggestions. Gisele Silva provided excellent research assistance. The standard disclaimer applies. 


\section{Introduction}

State and local politicians find themselves constrained by both politics - most notably, the need to win elections - and economics - most notably, the option of dissatisfied customers to go elsewhere with their human and/or physical capital. The welfare analysis of subjecting politicians to democratic voting - especially relative to dictatorship - has been largely favorable. (McGuire and Olson [1996]; Wittman [1995], [1989]) But the welfare analysis of the relocation option has been more equivocal. As RoseAckerman (1983) puts it, "A multiple-government system has little normative appeal if everyone has the same tastes and incomes and if the government apparatus is controlled by voters." (pp.25-26) Even when there is substantial heterogeneity of tastes, this must be weighed against the inability of decentralized governments to cope with interjurisdictional externalities. (Gordon [1983]; Donahue [1997]) Inman and Rubinfeld (1996) contrast this "optimal tax" account of federalism to the "political economy" view. While the former treats governments as a faithful agents of their citizens, the political economy perspective emphasizes that federalism helps mitigate the principal-agent problems of democracy. (Brennan and Buchanan [1980]; Frey and Eichenberger [1996]; Inman and Rubinfeld [1997]; Qian and Weingast [1997])

The current paper formally shows that even abstracting from heterogeneous preferences and interjurisdictional externalities, federalism can both improve and worsen the performance of democratic governments. I develop a model in which politicians compete electorally with another party within their state, and compete economically with a rival government outside their state. As in Lindbeck and Weibull (1987), Grossman and Helpman (1996), and Dixit and Londregan (1995, 1996, forthcoming a and b) elections work imperfectly: Voters treat parties as differentiated products. This model is rich enough to generate two quite different classes of equilibria. In the first class, the 
need to keep citizens from moving away leads politicians to improve their policies even if they are electorally secure. Federalism then mitigates the impact of the dominant party's monopoly power. In the second class of equilibria, however, the loyalists of each party tend to move to the state their party is expected to control. This process makes the political imperfections in both states more severe.

The next section describes the players and their objective functions. The third section solves the model and welfare ranks the possible equilibria. The fourth section examines the robustness of these findings to alternate assumptions. The fifth section analyzes the practical significance of the results. The sixth section concludes.

\section{Players, Preferences, and the Benchmark Equilibrium}

There are 2 state governments indexed by $k=\{1,2\}$. (Note that the interpretation of all variables is given in Table 1). Each state has 2 competing political parties $i$ and $j$. The players are thus 4 state political parties, plus a continuum of citizens whose measure $Y$ is normalized to 1 . Elections are decided by simple majority; for simplicity tied elections are counted as victories for $i$ in candidate equilibria where $i$ wins, and as victories for $j$ in candidate equilibria where $j$ wins. Play is simultaneous, and in any Nash equilibrium:

1. All citizens must vote for their most-preferred party in their state.

2. All political parties must offer platforms that maximize their expected utility.

3. All citizens must reside in their most-preferred state (if they have a choice). If they are indifferent between states they randomize with equal probabilities.

\subsection{Citizens}

Total wealth is assumed to be the same for all citizens, and is also normalized to equal

1. Citizen utility depends upon not only consumption of private and public goods, but also on the political environment. These tastes and the per-capita budget constraint 
yield citizens' indirect utility function, assumed to be of the following form:

(1) $\quad z_{c}^{k}=-\beta\left(G^{k}-G^{*}\right)^{2}+\Psi_{c} I^{k}$

$G^{*}$ is citizens' most-preferred size of government; the assumption of homogeneous policy preferences makes the positive and negative role of federalism in the model clearer. $I^{k}$ is an indicator variable which equals 1 if party $i$ is in power in state $k$, and 0 otherwise. $\quad \Psi_{c}$ is $c$ 's relative taste for party $i$ versus party $j$; a citizen will trade up to $\Psi_{c}$ in utility in order to be ruled by party $i$ rather than party $j . \Psi_{c}$ for the citizen population is uniformly distributed on the interval $[-.5+\Psi, .5+\Psi]$, where $\Psi \geq 0$ is both the average and the median value of $\Psi_{c}$.

There are a couple ways to interpret $\Psi_{c}$. Lindbeck and Weibull (1987) suggest that it captures parties' contrasting and relatively fixed commitments to important noneconomic policies, such as their stances on abortion and national defense. While most of the current paper assumes that both share the same power-maximizing objective, this does not rule out the possibility of different objectives along other margins. Alternately, in line with much of the empirical political science literature on party affiliation (e.g. Mutz and Mondak 1997; Sears et al 1980; Luttbeg and Martinez 1990), $\Psi_{c}$ could irreducibly reflect individuals' inherited partisan loyalties. Just as many sports fans root for "their" team even though all teams have the same objective function, many voters strictly prefer "their" party even if it acts the same as its competitor. For example, Catholic voters might continue voting for traditionally-preferred Democratic candidates even though

\footnotetext{
${ }^{1}$ More importantly, a later section shows that the simple model's results still hold when competing parties have different policy objective functions.
} 
platform changes leave them somewhat ideologically closer to Republicans. While such advantage gradually erodes, the erosion may be so gradual that for practical purposes each generation of politicians treats its level as fixed.

\subsection{Parties}

Controversy still surrounds political parties' objective functions. In Grossman and Helpman (1996) and Dixit and Londregan (1995; 1996; forthcoming b) political parties' objective is to maximize their votes.2 Dixit and Londregan's (forthcoming a) parties maximize a weighted average of votes and an ideological social welfare function; Alesina and Rosenthal (1995) similarly assume that parties advance divergent "leftist" and "rightist" ideologies subject to electoral constraints. In contrast, both Brennan and Buchanan (1980) and McGuire and Olson (1996) assume they seek to maximize their own power. $^{\text {B }}$ Caplan (1999a) presents empirical evidence on the relative merits of the ideological and power-maximizing views of party motivation, finding that both theories have some validity. The core of this paper builds on the power-maximizing assumption because it makes the model more tractable and the results clearer: Unlike ideological parties, all power-maximizing parties want to shirk in the same way. Yet powermaximization is not necessary for the main results: Section four shows that if parties have divergent ideologies, the modified model is nearly isomorphic. The powermaximizing motive of the parties is formalized by assuming that parties' utility increases

${ }^{2}$ On the theory of politicians with preferences over both policies and electoral victory, see Wittman (1983).

${ }^{3}$ McGuire and Olson's (1996) self-interested autocrats maximize their tax revenues minus their expenditures; in consequence, government unconstrained by elections is too small. Brennan and Buchanan, however, model politicians as constrained maximizers of government spending, so government spending tends to be too large. These two approaches are probably more similar than they appear. Direct appropriation of surplus tax revenues is normally impermissible in democracies; politicians therefore face the public-sector equivalent of rate-of-return regulation, with the permissible return capped at zero. The rational response of a self-interested autocrat or elected power-maximizing parties - would be to eliminate monopoly profits by raising costs. 
monotonically as the size of government they control grows:

$$
\begin{aligned}
& u_{i}^{k}=I^{k} * G_{i}^{k} Y^{k} \\
& u_{j}^{k}=\left(1-I^{k}\right) * G_{j}^{k} Y^{k}
\end{aligned}
$$

where $G_{i}^{k}$ and $G_{j}^{k}$ are the political platforms offered in state $k$ by parties $i$ and $j$.

\subsection{The Benchmark Regime: Politicians Constrained Solely by Elections}

Suppose a regime has democratic elections, but citizens and their wealth cannot move to another locality. Each state has demographically identical populations of .5 irrespective of policy. This lack of mobility could be interpreted as a system of immigration controls, or as the result of a federal tax and grant system that leaves no incentive for relocation at the margin. Using (1), and defining $\delta^{k} \equiv\left(G^{k}-G^{*}\right)^{2}$, it can be seen that citizens vote for party $i$ if:

$$
-\beta \delta_{i}^{k}+\Psi_{c} \geq-\beta \delta_{j}^{k}
$$

and for party $j$ otherwise. Similarly, the political parties only need to worry about beating each other, so (2) and (3) become:

$$
u_{i}^{k}=I^{k} * .5 G_{i}^{k}
$$

$u_{j}^{k}=\left(1-I^{k}\right)^{*} .5 G_{j}^{k}$

Given majority rule, it will then not be an equilibrium for both political parties to offer the median preference. Since by assumption $\Psi \geq 0$, party $i$ wins with certainty if it plays $G^{*}$. Unless $\Psi=0, i$ can still win with certainty (and increase its utility) even if it plays somewhat more. Party $i$ will want to keep increasing the offered level of government until it drives the percentage of votes it receives down to .5 : 


$$
(\Psi+.5)-\beta\left(\delta_{i}^{k}-\delta_{j}^{k}\right)=.5
$$

Due to disadvantaged status, in equilibrium party $j$ will never win. ${ }^{⿴}$ However, neither party will have an incentive to change its behavior only if $j$ maximizes its votes (which is equivalent to minimizing is votes):

(8) $\quad \min _{G_{j}^{k}}(\Psi+.5)-\beta\left(\delta_{i}^{k}-\delta_{j}^{k}\right)$

Solving (8) reveals that $j$ 's vote-maximizing strategy is to set $G_{j}^{k}=G^{*}$. One can find $i$ s best-response by plugging $G_{j}^{k}=G^{*}$ into (7), yielding:

(9) $\quad G_{i}^{k}=G^{*}+\sqrt{\frac{\Psi}{\beta}}$

In the benchmark equilibrium, then, the party with the greater political advantage always wins, but is constrained in its choices by the presence of the alternative, less popular party. The disadvantaged party offers to set the size of government equal to citizens' bliss point. The advantaged party's deviation from citizens' most-preferred level is an increasing function of the magnitude of the political advantage of the dominant party divided by the loss-sensitivity parameter. It goes as far as it can get away with without losing office.

\subsection{Welfare Analysis of the Benchmark Regime}

Treating $\Psi_{c}$ as a random variable, one can calculate citizens' expected utility in a given regime. In general:

$$
E\left(z_{c}\right)=Y^{1} E\left(z_{c}^{1}\right)+Y^{2} E\left(z_{c}^{2}\right)
$$

\footnotetext{
${ }^{4}$ Except in the special case where $\Psi=0$.
} 
Using (1), defining $\Psi^{k}$ as the median value of $\Psi_{c}$ in state $k$, and noting that the median and mean value of $\Psi_{c}$ are equal:

$$
E\left(z_{c}\right)=Y^{1}\left(-\beta \delta^{1}+\Psi^{1} I^{1}\right)+Y^{2}\left(-\beta \delta^{2}+\Psi^{2} I^{2}\right)
$$

Computing citizens' expected utility in the benchmark regime is straightforward. $G_{i}^{k}=G^{*}+\sqrt{\Psi / \beta}, Y^{k}=.5$ and $\Psi^{k}=\Psi$ since there is no mobility, and $I^{k}=1$ since party $i$ controls both states. Substituting these into (11) reveals that the benchmark utility level is 0 :

$$
E\left(z_{c}\right)=-\beta\left(\sqrt{\frac{\Psi}{\beta}}\right)^{2}+\Psi=0
$$

\section{Political Equilibrium and Welfare with Both Mobility and Voting}

This section characterizes the equilibria of the game with both free elections and unconstrained mobility, then compares the expected utility of these equilibria to that of the benchmark regime. $Y^{k}, \Psi^{k}$, and $I^{k}$ become endogenous functions of policy, as one would expect for members of democratic federal systems. Unlike the simplified game without mobility, which has the unique benchmark equilibrium, the more complex game with both voting and mobility can have multiple equilibria. These are possible because unrestricted movement directly affects $\Psi^{k}$, the median of the distribution of $\Psi_{c}$ in state $k$, which in turn influences political outcomes. There are four such candidate equilibria: $\left\{I^{1}, I^{2}\right\}$ can equal $\{1,1\},\{0,0\},\{1,0\}$, or $\{0,1\}$. Table 2 summarizes this section's results, dividing equilibria into "good" equilibria where expected utility is weakly greater than the benchmark level, and "bad" equilibria where it is strictly lower.

3.1. Party $i$ Wins in Both States: $\left\{I^{1}, I^{2}\right\}=\{1,1\}$

If party $i$ is expected to win in both states, there is no incentive to relocate on the basis of 
partisan preferences, so $\Psi^{k}=\Psi$. Whichever state has the lower value of $\delta^{k}$ accordingly gets $100 \%$ of the population. As in the Bertrand duopoly game, this leaves only one Nash equilibrium in which the ruling party in both states sets $\delta^{k}=0$. Both states get exactly half the population. To sustain this equilibrium, both chapters of party $i$ need merely ensure that they win elections in both states. As shown in 2.3, party $i$ can always win the election if $\Psi^{k} \geq 0$, so an equilibrium with $\left\{I^{1}, I^{2}\right\}=\{1,1\}$ always exists.

Expected utility in this regime is clearly higher than in the benchmark case, which has expected utility of 0 . Using (11):

$$
E\left(z_{c}\right)=Y^{1}\left(-\beta \delta_{i}^{1}+\Psi^{1} I^{1}\right)+Y^{2}\left(-\beta \delta_{i}^{2}+\Psi^{2} I^{2}\right)=.5(0+\Psi)+.5(0+\Psi)=\Psi \geq 0
$$

Hence, this is always one of the "good" equilibria where mobility makes democracy work (weakly) better. Note further that there is no reason to regard this as an unstable equilibrium, as identical communities can be in a simple Tiebout model with heterogeneous citizens. In a world with small random perturbations, the $i$ parties would adjust by aiming for a larger victory margin.

3.2. Party $j$ Wins in Both States: $\left\{I^{1}, I^{2}\right\}=\{0,0\}$

If party $j$ is expected to win in both states, there is no incentive to relocate on the basis of partisan preferences, so $\Psi^{k}=\Psi$. As shown in 2.3 , this candidate equilibrium will not exist if $\Psi^{k}>0$. If $\Psi=0$, (13) shows it yields the same welfare level as the benchmark. 3.3. Party $i$ Wins in One State, Party $j$ Wins in the Other: $\left\{I^{1}, I^{2}\right\}=\{1,0\}$ or $\{0,1\}$

The numbering of the states is arbitrary, so the equilibrium conditions for $\left\{I^{1}, I^{2}\right\}=\{1,0\}$ and $\left\{I^{1}, I^{2}\right\}=\{0,1\}$ are essentially identical. For simplicity, then, this section looks only at $\left\{I^{1}, I^{2}\right\}=\{1,0\}$, where party $i$ wins in state 1 and party $j$ wins in state 2 . 
In any equilibrium, note that citizens in state $k$ are indifferent between voting for $i$ and $j$ when:

$$
\Psi_{c}=\beta\left(\delta_{i}^{k}-\delta_{j}^{k}\right)
$$

Note further that in any equilibrium, the median voter must weakly prefer the winner, and losing parties' platforms set the size of government equal to $G^{*}$. Using (14) and these two facts permits the derivation of both electoral victory constraints:

$$
\beta \delta_{i}^{1} \leq \Psi^{1}
$$

$$
\beta \delta_{j}^{2} \leq-\Psi^{2}
$$

Citizens are indifferent between living under $i$ in state 1 and under $j$ in state 2 when:

$$
\Psi_{c}=\beta\left(\delta_{i}^{1}-\delta_{j}^{2}\right)
$$

All citizens with $\Psi_{c}>\beta\left(\delta_{i}^{1}-\delta_{j}^{2}\right)$ strictly prefer state 1 , and all with $\Psi_{c}<\beta\left(\delta_{i}^{1}-\delta_{j}^{2}\right)$ strictly prefer state $2{ }^{5}$ (Diagram 1$)$ The fraction of citizens in each state is thus given by:

$$
\begin{aligned}
& Y^{1}=.5+\Psi-\beta\left(\delta_{i}^{1}-\delta_{j}^{2}\right) \\
& Y^{2}=.5-\Psi+\beta\left(\delta_{i}^{1}-\delta_{j}^{2}\right)
\end{aligned}
$$

The demand for residence in state 1 is (a) an increasing linear function of the mean preference for party $i$ over party $j$, (b) a decreasing function of the deviations from voters' bliss points in state 1 , and (c) an increasing function of the deviations from voters' bliss

\footnotetext{
${ }^{5}$ For purposes of later welfare analysis, note that this means that the median and mean values of $\Psi_{c}$ remain identical.
} 
points in state 2. The opposites hold for residence in state 2.

The median value of $\Psi_{c}$ in both states can be derived from the distributions implied by (18) and (19):

$$
\begin{aligned}
& \Psi^{1}=\frac{.5+\Psi+\beta\left(\delta_{i}^{1}-\delta_{j}^{2}\right)}{2} \\
& \Psi^{2}=\frac{-.5+\Psi+\beta\left(\delta_{i}^{1}-\delta_{j}^{2}\right)}{2}
\end{aligned}
$$

Plugging (20) into (15) and (21) into (16) yields is electoral victory constraint in state 1 and $j$ 's corresponding constraint in state 2 :

$$
\beta \delta_{i}^{1} \leq .5+\Psi-\beta \delta_{j}^{2}
$$

$$
\beta \delta_{j}^{2} \leq .5-\Psi-\beta \delta_{i}^{1}
$$

This means that there are four sub-cases to consider: (a) the voting constraint binds in both states; (b) the voting constraint binds in state 1 but not state 2 ; (c) the voting constraint binds in state 2 but not state 1; (d) the voting constraint binds in neither state.

\section{A. Voting Constraint Binds in Both States}

If the voting constraint binds in both states, then (22) and (23) both hold with equality. This is only possible if $\Psi=0$, in which case $\beta \delta_{i}^{1}=\beta \delta_{j}^{2}=.25, Y^{1}=Y^{2}=.5, \Psi^{1}=.25$, and $\Psi^{2}=-.25$. Plugging these values into (11) show that this equilibrium is welfareinferior to the benchmark:

$$
E\left(z_{c}\right)=.5(-.25+.25)+Y^{2}(-.25+0)=-.125<0
$$

Thus, this is always a "bad" equilibrium where mobility amplifies rather than mitigates the 
effect of imperfect political competition.

\section{B. Voting Constraint Binds in State 1 but not State 2}

Proof by contradiction shows this equilibrium will never exist. Suppose it did: then (22) holds with equality, while (23) holds as a strict inequality, so: $\beta \delta_{i}^{1}=.5+\Psi-\beta \delta_{j}^{2}$ and $\beta \delta_{j}^{2}<.5-\Psi-\beta \delta_{i}^{1} . \quad$ Plugging the equality into the inequality implies: $\beta \delta_{j}^{2}<.5-\Psi-\left[.5+\Psi-\beta \delta_{j}^{2}\right] . \quad$ Cancelling terms leaves $0<-2 \Psi$, which is a contradiction since $\Psi \geq 0$. Intuitively, since $i$ is less constrained than $j, j$ must be constrained in equilibrium if $i$ is.

C. Voting Constraint Binds in State 2 but not State 1

In this case, (23) holds with equality for party $j$ in state 2. Party $i$ in state 1 maximizes $G_{i}^{1} Y^{1}$ subject to (18):

$$
\max _{G_{i}^{1}} G_{i}^{1}\left\{.5+\Psi-\beta\left(\delta_{i}^{1}-\delta_{j}^{2}\right)\right\}
$$

Differentiating (25) and setting it equal to zero:

$$
\left\{.5+\Psi-\beta\left(\delta_{i}^{1}-\delta_{j}^{2}\right)\right\}+G_{i}^{1}\left\{-2 \beta\left(G_{i}^{1}-G^{*}\right)\right\}=0
$$

Implying:

$$
G_{i}^{1}=\frac{4 G^{*}+\sqrt{4 G^{* 2}+\frac{6}{\beta}+12 \frac{\Psi}{\beta}+12 \delta_{j}^{2}}}{6}
$$

Since (23) binds, it may be used to substitute out for party j's strategy:

$$
G_{i}^{1}=\frac{4 G^{*}+\sqrt{4 G^{* 2}+\frac{6}{\beta}+12 \frac{\Psi}{\beta}+\frac{12}{\beta}\left[.5-\Psi-\beta \delta_{i}^{1}\right]}}{6}
$$

\section{Simplifying:}


(29)

$$
G_{i}^{1}=\frac{4 G^{*}+\sqrt{4 G^{* 2}+\frac{12}{\beta}-12 \delta_{i}^{1}}}{6}
$$

$$
G_{i}^{1}=\frac{6 G^{*}+\sqrt{4 G^{* 2}+\frac{16}{\beta}}}{8}
$$

(31) $\delta_{i}^{1}=\left[\frac{-2 G^{*}+\sqrt{4 G^{* 2}+\frac{16}{\beta}}}{8}\right.$

Plugging (31) back into j's constraint:

$$
\beta \delta_{j}^{2}=.5-\Psi-\beta\left[\frac{-2 G^{*}+\sqrt{4 G^{* 2}+\frac{16}{\beta}}}{8}\right]^{2}
$$

Comparing the welfare properties of this equilibrium to the benchmark is more complicated than previous cases. Substituting (18)-(21) into (11):

$$
E\left(z_{c}\right)=\left\{.5+\Psi-\beta\left(\delta_{i}^{1}-\delta_{j}^{2}\right)\right\}\left[-\beta \delta^{1}+\left\{\frac{.5+\Psi+\beta\left(\delta_{i}^{1}-\delta_{j}^{2}\right)}{2}\right\}+\left\{.5-\Psi+\beta\left(\delta_{i}^{1}-\delta_{j}^{2}\right)\right\}\left[-\beta \delta^{2}\right]\right.
$$

This expression reduces to:

$$
E\left(z_{c}\right)=.5\left[\beta\left(\delta_{i}^{1}-\delta_{j}^{2}\right)\right]^{2}-\Psi\left[\beta\left(\delta_{i}^{1}-\delta_{j}^{2}\right)\right]-.5\left[\beta\left(\delta_{i}^{1}+\delta_{j}^{2}\right)\right]+.5\left[\Psi^{2}+\Psi+.25\right]
$$

The appendix shows that this particular equilibrium's expected utility level could be greater than, less than, or equal to the expected utility level of the benchmark equilibrium. Equilibria where $\beta \delta_{i}^{1}$ lies strictly inside the interval 
$\left(\frac{1-\sqrt{1-8 \Psi}}{4}, \frac{1+\sqrt{1-8 \Psi}}{4}\right.$ are welfare-inferior; those where $\beta \delta_{i}^{1}$ is strictly outside that interval are welfare-superior. Mobility combined with elections may yield worse results than elections singly.

D. Voting Constraint Does Not Bind in Either State

In this last case, party $i$ in state 1 maximizes $G_{i}^{1} Y^{1}$ subject to (17), and party $j$ in state 2 maximizes $G_{j}^{2} Y^{2}$ subject to (18). In equilibrium, (27) holds. So does an analogous equation for $j$ 's best response:

$$
G_{j}^{2}=\frac{4 G^{*}+\sqrt{4 G^{* 2}+\frac{6}{\beta}-12 \frac{\Psi}{\beta}+12 \delta_{i}^{1}}}{6}
$$

Deriving an analytical or even approximate solution to this set of equations is involved, but unnecessary. Considering the special case where $\Psi=0$ is sufficient to show that this equilibrium can be welfare-superior or welfare-inferior to the benchmark case, depending on parameter values. Then there is a simple symmetric equilibrium, where $G_{i}^{1}=G_{j}^{2}$. Using (27):

$$
G_{i}^{1}=\frac{4 G^{*}+\sqrt{4 G^{* 2}+\frac{6}{\beta}+12 \frac{\Psi}{\beta}+12\left(G_{i}^{1}-G^{*}\right)^{2}}}{6}
$$

Implying:

$$
G_{i}^{1}=G_{j}^{2}=\frac{1}{2} G^{*}+\sqrt{\frac{G^{* 2}}{4}+\frac{1}{4 \beta}}
$$

Plugging into (34), it can be seen that expected utility exceeds that of the benchmark iff:

$$
-\beta\left[-\frac{1}{2} G^{*}+\sqrt{\frac{G^{* 2}}{4}+\frac{1}{4 \beta}}\right]^{2}+.125>0
$$


which holds when:

$$
G^{*}>\frac{1}{\sqrt{8 \beta}}
$$

Conversely, this equilibrium is welfare-inferior to the benchmark when $G^{*}<1 / \sqrt{8 \beta}$. Like the previous case, then, this can be either a "good" or a "bad" equilibrium.

\section{Robustness of the Model}

The model solved in section three uses a number of non-standard assumptions. While these do simplify the results, this section shows that the paper's central conclusions are fairly robust. They remain largely unchanged if: (1) there is one "small-government" and one "big-government" party; (2) if there are heterogeneous ideal policy points; (3) if there are moving costs between jurisdictions; (4) if there are more than 2 jurisdictions. The findings change more if: (5) parties coordinate at the national level; or (6) the timing and commitment assumptions change. The following six sections examine how changing one assumption at a time in the basic model - keeping all of the others fixed - alters the results.

\subsection{Opposing Ideologies}

In my model, both parties maximize the size of government. A more common modeling strategy, however, is to assume that parties have opposing ideologies, such as "smallgovernment" versus "big-government." Suppose, then, that party $j$ 's objective function is still given by (3), but party i's utility is an increasing function of the size of the private sector conditional on holding power:

$$
u_{i}^{k}=I^{k} *\left(1-G_{i}^{k}\right) Y^{k}
$$

Since the critical variable is squared equilibrium deviations from voters' ideal point, a surprising fraction of the model's results go through nearly unchanged. In the simplified 
version of the model without mobility, $i$ deviates as far as possible from voter preferences as it can without losing office, so $\delta_{i}^{k}$ remains $\Psi / \beta$. The only difference is in the direction of deviation: (9) becomes:

(9)' $\quad G_{i}^{k}=G^{*}-\sqrt{\frac{\Psi}{\beta}}$

For the equilibrium with both voting and mobility, it is apparent that equations (15)-(23), being symmetric with respect to deviations from $G^{*}$, do not change. It is only necessary to remember that party $i$ deviates below $G^{*}$, while $j$ deviates above. Thus, the results for 3.1, 3.2, 3.3(a), and 3.3(b) go through unchanged.

Slight complications arise for the findings of sections 3.3(c) and (d). Now, party $i$ in state 1 maximizes $\left(1-G_{i}^{1}\right) Y^{1}$ subject to (18):

(25)' $\quad \max _{G_{i}^{1}}\left(1-G_{i}^{1}\right)\left\{.5+\Psi-\beta\left(\delta_{i}^{1}-\delta_{j}^{2}\right)\right\}$

From this one may derive the small-government party's optimal response to the policies of the big-government party in the other state:

$$
G_{i}^{1}=\frac{2\left(1+2 G^{*}\right)-\sqrt{4\left(1-G^{*}\right)^{2}+\frac{6}{\beta}+12 \frac{\Psi}{\beta}+12 \delta_{j}^{2}}}{6}
$$

Notice that this is not symmetric to (26): when $G^{*}>.5$, the small-government party's absolute deviation is greater than the large-government party's; when $G^{*}<.5$, the small-government party's absolute deviation is smaller. Otherwise, however, the modified model's results for the remaining cases parallel those of 3.3(c) and 3.3(d).

\subsection{Heterogeneous Policy Preferences}

Most models of federalism assume that citizens have diverse tastes about policy, not a 
single shared $G^{*}$ as the current paper does. Suppose then that there are equal proportions of two types of voters, one whose most-preferred size of government is $G^{B}$ while the other's is $G^{S}$, with $G^{B}>G^{S}$. The voters are otherwise identical; in particular, for both types, the distribution of $\Psi_{c}$ is the same. The set of equilibria of this modified version of the model is complex because both the distribution of policy preferences as well as the distribution of $\Psi_{c}$ are endogenous. An appendix available from the author discusses the most straightforward cases, and shows that with heterogeneous preferences there are still "good" and "bad" equilibria.

\subsection{Moving Costs and Initial Citizen Distribution}

In the version of the model in section two, moving costs are effectively infinite. In section three, mobility is costless. What about intermediate cases? An earlier version of this paper shows that most of the results from section three persist. The main difference is that with mobility costs, inter-jurisdictional competition is imperfect. Even when party $i$ rules in both states, mobility cannot pressure parties to offer $G^{*}$. The welfare analysis is largely unchanged; the main difference is that it is necessary to take account of realized mobility costs when calculating the net welfare impact of federalism. (Caplan 1999b)

With positive mobility costs, the initial distribution of citizens begins to matter too. In general, a less-than-perfectly-evenly distributed population enhances the advantages of federalism. The disadvantage of federalism is that citizens with similar party preferences cluster together, leading to weak political competition. If citizens with similar party preferences are initially clustered, however, the marginal disadvantages of mobility decline and the marginal advantages increase. In effect, if citizens cluster ex ante, the relevant "benchmark" equilibrium's welfare level is lower, so it is more likely that the equilibrium with mobility is welfare-superior. 


\subsection{More Jurisdictions}

Increasing the number of jurisdictions, while retaining the assumption of costless mobility, can yield a first-best outcome. With four jurisdictions, there exists an equilibrium where party $i$ rules in 2 states, party $j$ rules in the other 2 , the equilibrium level of government in all four states is $G^{*}$, and everyone lives under their mostpreferred political party. In general, so long as there is costless mobility, if one party rules any two states, mobility pressures both to set the size of government to $G^{*}$. Mobility costs naturally tend to weaken this result, as do heterogeneous policy preferences.

\subsection{Coordination}

Must the state chapters of each party set their platforms non-cooperatively? Perhaps all of the branches of party $i$ coordinate on a common strategy, as do the branches of party j. In the context of this paper's model, there is no more reason to expect intra-party cooperation than inter-party cooperation. However, this could change if the national dimension of this federal system's politics were modeled more explicitly. The state parties might, for example, follow their national affiliates in order to get a normal level of federal grants. The equilibria where the same party runs both states then look markedly worse: rather than competing in a Bertrand-like fashion, they might not compete at all.

\subsection{Timing and Commitment}

The model assumes that all players make their moves simultaneously. In this case, there can be no commitment problem. Altering this timing assumption could clearly alter the game's results, particularly if there is no credible commitment technology for parties. If people make their location decisions first, and parties subsequently set policy, then at 
the time of decision, elections are the only factor constraining parties' platforms.

The model must then be solved by backwards induction. Note that in equilibrium, voting constraints must bind in both states, so there are only two cases that need to be analyzed. In the first, $i$ wins in both states, and sets $G_{i}^{1}=G_{i}^{2}=\sqrt{\Psi / \beta}$. The welfare level is no different from that without mobility. In the second, $i$ wins in one state, and $j$ wins in the other. In this case, (15) and (16) reduce to: $\beta \delta_{i}^{1}=\Psi^{1}$ and $\beta \delta_{j}^{2}=-\Psi^{2}$. Substituting these values into (20) and (21) and solving for $\Psi^{1}$ and $\Psi^{2}$ reveals that this equilibrium exists only if $\Psi=0$ - which is, as Table 2 shows, welfare-inferior to the benchmark.

While the model's findings are definitely sensitive to the timing assumption, moving to a repeated game structure would probably restore the relevance of the results for the simultaneous game. Given sufficiently low discount rates, the "cooperative" solution where parties implement promises they make prior to citizens' location decisions should be sustainable. Parties would not take advantage of one turn's electoral slack because this would reduce their state's population in subsequent turns.

\section{Implications for Federalism}

The importance of heterogeneous preferences as an argument for decentralization, and interstate spillovers as an argument against, appears repeatedly in the optimal federalism literature. As Gordon (1983) argues:

There may be advantages to decentralizing government decision-making. Local governments, being "closer to the people," may better reflect individual preferences. The diversity of policies of local governments allows individuals to move to that community best reflecting their tastes. Competition among communities should lead to greater efficiency and innovation. However, this paper has shown the many ways in which decentralized decision-making can lead to inefficiencies, since a local government will ignore the effects of its decisions on the utility levels of nonresidents. (p.584) 
My model abstracts from both heterogeneity and spillovers in order to focus on the interaction between imperfect political competition and federalism. The most notable result is that there are "good" equilibria where mobility mitigates political imperfections (or at least does not make them worse) and "bad" equilibria where mobility intensifies them. (Table 2) Even in a world where citizens' policy tastes were uniform and state policies affected only residents, federalism is not necessarily useless - or necessarily beneficial.

\subsection{The "Good" Equilibria}

The intuition behind the "good" equilibria is straightforward: if politicians take excessive advantage of imperfect political competition, citizens leave. Power-maximizing politicians may therefore moderate their excesses not because they fear electoral defeat, but because population outflows reduce their power. If politicians win supermajorities by doing exactly what citizens want, they have an incentive to make government bigger; if the supermajority is ample enough, the ruling party will even have a supermajority at the unconstrained maximum value of $G_{i}^{k} Y^{k}$. At that point there is no longer any reason to make $G_{i}^{k}$ larger because it cuts both the winning party's share of the votes and $G_{i}^{k} Y^{k}$.

State and local governments in federal democracies usually face both political and economic constraints. This might indicate that constitutional framers think that the "good" equilibria are empirically predominant; if the framers foresee imperfect electoral competition, they can mitigate it by sub-dividing the polity. In this case, Brennan and Buchanan (1980) are correct to argue that that inter-jurisdictional competition reduces 
the power of Leviathan.

\subsection{The "Bad" Equilibria}

But matters are more complicated: The interaction of mobility and imperfect political competition can also make the monopoly power of government greater. The underlying intuition is that if voters with opposite party tastes divide up into their own "safe districts," then competitive elections may be absent in every state. If a politician implements bad policies, the first people to exit are those who most dislike the current office-holders. This shifts the absolute value of median party taste $\Psi_{c}$ further from zero, making worse policies electorally sustainable. This is possible because living under one's preferred political party is a private good, but the welfare properties of the political equilibrium are a public good. Perfect sorting of citizens according to the sign of $\Psi_{c}$ maximizes the realized sum of citizens' party preferences, but at the same time makes policy imperfections as large as possible.

The "bad" equilibria suggest one possible economic interpretation of "machine politics." (Dixit and Londregan 1996) If the Democrats control the San Francisco city government, it tends to induce out-migration on the part of strong Republican partisans and further cement the Democrats' electoral margin. In consequence not only do the political imperfections in San Francisco become more severe; at the same time, the staunch Republicans who move to Republican districts also exacerbate the political imperfections in their new localities. The "bad" equilibria offer a novel explanation for why voters may simultaneously dislike incumbents' policies, yet continue to vote for them: They have self-selected into districts with strong partisan loyalties. Rational power-maximizing politicians take advantage of the situation by deliberately deviating from voters' policy 
preferences. So long as the reigning politicians' deviation from voter preferences does not exceed the median degree of party loyalty, the political machine can stay in power indefinitely.

What is particularly interesting about the "bad" equilibria is that they can emerge even if $\Psi=0$, i.e., if the median voter in the overall population has no party preference whatever. If voters expect $i$ to win in one state and $j$ in the other, it makes sense for people with $\Psi_{c}>0$ to move to the state where $i$ rules, and for the people with $\Psi_{c}<0$ to move to the state where $j$ rules. Imperfect political competition itself can therefore arise endogenously because a balanced population tends to sub-divide into two imbalanced populations. It is therefore unnecessary to assume that the distribution of $\Psi_{c}$ is skewed towards one party to generate imperfect political competition.

\subsection{Interpreting the Model}

While parameter values do restrict the set of possible outcomes, there are still frequently multiple equilibria. Self-fulfilling expectations sustain these equilibria: the general expectation that party $i$ will win in both states makes it possible for party $i$ to actually do so; yet the expectation that party $j$ would control one state might have made that a possibility as well. If a "turn" is interpreted as a relatively short time period, this argument seems to require an implausibly high degree of inter-state mobility. Yet if the relevant "turn" is longer, the compounded effect of a low annual rate of migration could be appreciable. The model may thus be best suited for the analysis of long-lasting state or urban political machines, where historical experience gives rise to voters' self-fulfilling expectations, and migrants respond to durable political patterns.

\section{Conclusion}


The model presented in this paper appears to be the first in which citizens' mobility endogenizes political imperfections. It is intended not as a substitute to but as a complement for the more traditional approach to optimal federalism (Gordon [1983]), showing that there are additional arguments for and against federalism when political competition works imperfectly. There are "good" equilibria where citizen mobility dampens the importance of imperfect political competition, and "bad" equilibria where citizen mobility creates "safe districts," in which the political process is even less competitive.

There are several possible outlets for further research building on this paper's insights. While the model is relatively simple, it shows that citizen migration and political imperfection can interact in sometimes unexpected ways. These may be of some practical importance in understanding e.g. the recent waves of secessions and political and economic unions. Since the model can give rise to both "good" and "bad" equilibria for the same set of parameters, further examination of the conditions under which federalism mitigates imperfect political competition is also in order. The widespread use of federalist institutions perhaps suggests that the "good" equilibria occur most frequently. On the other hand, continuing dissatisfaction with the performance of government might be a sign that voters are stuck in a "bad" equilibrium in which citizen mobility has amplified the inherent imperfections of the political process. 
Table 1: Summary of the Model's Variables

\begin{tabular}{|l|l|}
\hline Exogenous & Interpretation \\
\hline$G^{*}$ & citizens' most preferred quantity of public goods \\
\hline$\beta$ & utility loss sensitivity parameter for public goods \\
\hline$\Psi_{c}$ & intensity of citizen c's preference for party $i$ \\
\hline$Y$ & total population/output of economy; normalized to =1 \\
\hline$\Psi$ & median (and mean) intensity of population's preference for party $i$ \\
\hline$G^{B}, G^{S}$ & two types of citizens' most preferred quantity of public goods, $G^{B}>G^{S}$ \\
\hline Endogenous & Interpretation \\
\hline$G^{k}$ & quantity of public good in state $k$ \\
\hline$z_{c}^{k}$ & indirect utility function of citizen $c$ in state $k$ \\
\hline$I^{k}$ & indicator variable=1 if party $i$ wins in state $k,=0$ otherwise \\
\hline$u_{i}^{k}, u_{j}^{k}$ & utility function of state parties $i, j$ in state $k$ \\
\hline$Y^{k}$ & total population/output in state $k$ \\
\hline$\delta^{k}$ & squared deviation of $G^{*}$ in state $k$ \\
\hline$\Psi^{k}$ & the median of the distribution of $\Psi_{c}$ in state $k$ \\
\hline
\end{tabular}

Table 2: Existence and Welfare Properties of Candidate Equilibria

\begin{tabular}{|l|l|l|}
\hline Case & Possible "Good" Eq.? & Possible "Bad" Eq.? \\
\hline$\left\{I^{1}, I^{2}\right\}=\{1,1\}$ & Yes. & No. \\
\hline$\left\{I^{1}, I^{2}\right\}=\{0,0\}$ & Yes. (only if $\Psi=0)$ & No. \\
\hline $\begin{array}{r}\left\{I^{1}, I^{2}\right\}=\{1,0\} \text { or }\{0,1\} ; \\
\text { Voting constraint binds in... }\end{array}$ & & \\
\hline ... both states & No. & Yes (only if $\Psi=0)$ \\
\hline ... state 2 but not state 1 & Yes. & Yes. \\
\hline ... state 1 but not state 2 & \multicolumn{2}{|c|}{ Does not exist. } \\
\hline ... neither state & Yes. & Yes. \\
\hline
\end{tabular}

Diagram 1: Party Preferences when $\left\{I^{1}, I^{2}\right\}=\{1,0\}$

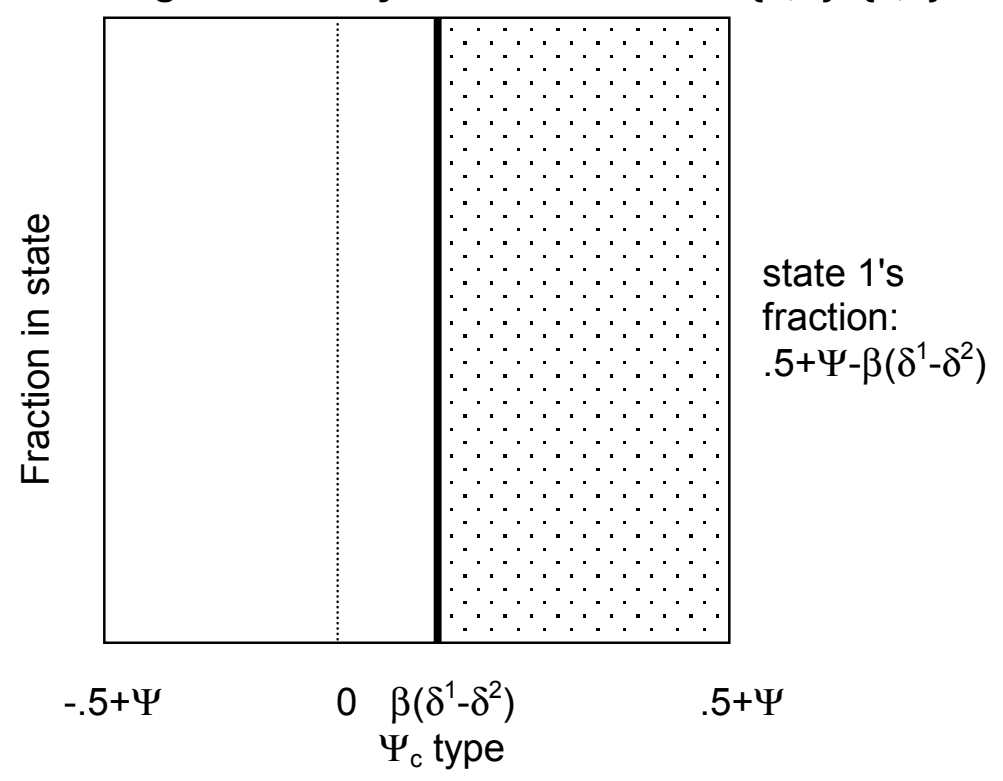




\section{Appendix: Welfare Properties of Equilibrium 3.3(c)}

Recall that the expected utility of the benchmark is 0 . Using (34), it can be seen that the utility of equilibrium 3.3(c) equals the utility of the benchmark iff:

$$
\left[\beta\left(\delta_{i}^{1}-\delta_{j}^{2}\right)\right]^{2}-2 \Psi\left[\beta\left(\delta_{i}^{1}-\delta_{j}^{2}\right)\right]-\left[\beta\left(\delta_{i}^{1}+\delta_{j}^{2}\right)\right]+\left[\Psi^{2}+\Psi+.25\right]=0
$$

Conversely, if the left-hand side of the above expression is greater than zero, equilibrium 3.3(c) is better than the benchmark; if less than zero, worse.

From (31) and (32):

$$
\beta\left(\delta_{i}^{1}+\delta_{j}^{2}\right)=.5+\Psi
$$

Substituting (a2) into (a1) and re-arranging terms implies:

$$
\left[\beta\left(\delta_{i}^{1}-\delta_{j}^{2}\right)\right]^{2}-2 \Psi\left[\beta\left(\delta_{i}^{1}-\delta_{j}^{2}\right)\right]+\Psi^{2}+2 \Psi-.25=0
$$

(a3) has two solutions:

$$
\left[\beta\left(\delta_{i}^{1}-\delta_{j}^{2}\right)\right]=\Psi \pm \frac{\sqrt{1-8 \Psi}}{2}
$$

From (31) and (32), we know that:

$$
\beta\left(\delta_{i}^{1}-\delta_{j}^{2}\right)=2 \beta\left[\frac{-2 G^{*}+\sqrt{4 G^{* 2}+\frac{16}{\beta}}}{8}\right]^{2}-.5+\Psi
$$

Combining (a4) and (a5), and simplifying:

$$
\beta\left[\frac{-2 G^{*}+\sqrt{4 G^{* 2}+\frac{16}{\beta}}}{8}\right\rceil^{2}=\frac{1 \pm \sqrt{1-8 \Psi}}{4}
$$

When (a6) holds with equality, then, equilibrium 5.3(c) and the benchmark offer the same expected welfare levels. Equilibrium 5.3(c) is welfare-inferior to the benchmark iff

$$
\beta \delta_{i}^{1}=\beta\left[\frac{-2 G^{*}+\sqrt{4 G^{* 2}+\frac{16}{\beta}}}{8}\right]^{2} \text { lies within the interval: }\left(\frac{1-\sqrt{1-8 \Psi}}{4}, \frac{1+\sqrt{1-8 \Psi}}{4}\right. \text {, and }
$$

welfare-superior to the benchmark iff it lies outside that interval. 


\section{References}

Alesina, Alberto, and Howard Rosenthal. Partisan Politics, Divided Government, and the Economy New York: Cambridge University Press. (1995)

Bender, Bruce, and John R. Lott, Jr. "Legislator Voting and Shirking: A Critical Review of the Literature" Public Choice, 87, (1996): 67-100.

Brennan, Geoffrey, and Buchanan, James M. The Power to Tax: Analytical Foundations of a Fiscal Constitution Cambridge: Cambridge University Press. (1980).

Caplan, Bryan. "Has Leviathan Been Bound? A Theory of Imperfectly Constrained Government with Evidence from the States." Submitted to Economic Inquiry. (1999a).

Caplan, Bryan. "When Is Two Better Than One? How Federalism Mitigates and Intensifies Imperfect Political Competition." Unpub. ms, George Mason University. (1999b)

Dixit, Avinash, and John Londregan. "Redistributive Politics and Economic Efficiency." American Political Science Review, 89, (1995): 856-866.

. "The Determinants of Success of Special Interests in Redistributive Politics." Journal of Politics, 58, (1996):1132-1155.

. (forthcoming a), "Ideology, Tactics, and Efficiency in Redistributive Politics." Quarterly Journal of Economics.

\section{Public Economics.}

. (forthcoming b), "Fiscal Federalism and Redistributive Politics." Journal of

Donahue, John. "Tiebout, Or Not Tiebout? The Market Metaphor and America's

Devolution Debate." Journal of Economic Perspectives 11, (1997):73-82.

Frey, Bruno S., and Reiner Eichenberger. "To Harmonize or to Compete? That's Not the Question.” Journal of Public Economics, 60, (1996): 335-349.

Gordon, Roger H. "An Optimal Taxation Approach to Fiscal Federalism." Quarterly Journal of Economics, 95, (1983): 567-586.

Grossman, Gene, and Elhanan Helpman. "The Politics of Free-Trade Agreements." American Economic Review, 85, (1995): 667-690.

Studies, 63, (1996): 265-286.

"Electoral Competition and Special Interest Politics." Review of Economic

Inman, Robert P., and Daniel L. Rubinfeld. "Designing Tax Policy in Federalist

Economies: An Overview.” Journal of Public Economics, 60, (1996): 307-334.

64. . "Rethinking Federalism." Journal of Economic Perspectives 11, (1997): 43- 
Lindbeck, Assar, and Jorgen W. Weibull. "Balanced-Budget Redistribution as the Outcome of Political Competition.” Public Choice, 54, (1987): 273-297.

Lutbeg, Norman, and Michael Martinez. "Demographic Differences in Opinion, 19561984." In Long, Samuel, ed. Research in Micropolitics, 3, (1990): 83:118.

McGuire, Martin C., and Mancur Olson Jr., "The Economics of Autocracy and Majority Rule: The Invisible Hand and the Use of Force." Journal of Economic Literature, 34, (1996): 72-96.

Mutz, Diana, and Jeffrey Mondak. 1997. "Dimensions of Sociotropic Behavior: GroupBased Judgements of Fairness and Well-Being." American Journal of Political Science 41, 284-308.

Qian, Yingyi, and Barry Weingast. "Federalism as a Commitment to Preserving Market Incentives." Journal of Economic Perspectives, 11, (1997): 83-92.

Rose-Ackerman, Susan. "Tiebout Models and the Competitive Ideal: An Essay on the Political Economy of Local Government." in John Quigley (ed.), Perspectives on Local Public Finance and Public Policy, vol.1 Greenwich, CT: JAI Press. (1983).

Sears, David, Richard Lau, Tom Tyler, and Harris Allen. 1980. "Self-Interest vs. Symbolic Politics in Policy Attitudes and Presidential Voting." American Political Science Review 74, 670-684.

Wittman, Donald. "Candidate Motivation: A Synthesis of Alternative Theories." American Political Science Review, 77, (1983): 142-157.

.Why Democracies Produce Efficient Results." Journal of Political Economy,

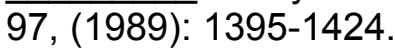

. The Myth of Democratic Failure: Why Political Institutions are Efficient

Chicago, IL: University of Chicago Press. (1995). 